gaseous state leaving behind the fixed carbon as char, which burns later in solid state. Since the heat of combustion of carbon is higher than that of volatile matter, a high proportion of fixed carbon content in unextracted samples has expectedly increased their calorific value (Table 2). Table 2 clearly demonstrates an increase in volatile matter content following extraction. The decomposition of cellulose at $260^{\circ}-350^{\circ} \mathrm{C}$ is mainly responsible for production of flammable volatiles. Except in coffee husk, a significant increase in volatile matter content is observed in all extracted samples (Table 2). Anatomically, extractives permeate both the cell wall and cell lumen ${ }^{5}$. They offer sufficient resistance to easy escape of volatiles from the biomass. The higher volatile matter content in extractive free samples may be due to easy escape of volatiles due to clear internal pathways ${ }^{5}$.

In any fuel, carbon-oxygen and carbon-hydrogen bonds contain lower energy than carbon-carbon bonds. Higher proportion of oxygen and hydrogen in biomass reduces the energy value of fuel ${ }^{13}$. Elemental analysis results clearly show that there is large variation in elemental composition among woody and non-woody biomass samples (Table 2). Variability in the amount of elemental carbon was more in non-woody biomass (35-50\%) than woody biomass (46-48\%). The extractive-free woody biomass samples were found to have significantly less elemental carbon. Elemental carbon of extracted woody samples reduced by $4.5-6.6 \%$. Lack of any particular trend in reducing elemental carbon following removal of extractives from non-woody samples can be attributed to complex biochemical composition of non-woody biomass. TEC in arecanut sample was found to be around $70 \%$; however, only $7 \%$ reduction in elemental carbon was observed in extractive-free biomass. This shows that not all extractives contribute towards elemental carbon or fixed carbon content in the biomass.

The fuel properties of woody and non-woody biomass samples have been analysed. The variability in fuel properties is found to be higher in non-woody biomass compared to woody biomass. The result shows that fuel properties of biomass are greatly influenced by extractive content. Extractive content in biomass contributes towards higher calorific value, ash content and fixed carbon content. The extractive-free biomass has higher volatile matter content. The elemental carbon in woody biomass reduces after extraction, but no particular trend is seen in non-woody biomass.

1. IEA, Technology roadmap-delivering sustainable bioenergy. International Energy Agency, 2017; https://webstore.iea.org/ technology-roadmap-delivering-sustainable-bioenergy

2. Mckendry, P., Energy production from biomass (part 1): overview of biomass. Bioresour. Technol., 2002, 83(1), 37-46.

3. Mckendry, P., Energy production from biomass (part 2): conversion technologies. Bioresour. Technol., 2002, 83, 47-54.

4. Sjostrom, E., Wood Chemistry, Fundamentals and Applications, Academic Press, New York, USA, 2003, 2nd edn.
5. Walker, J. C. F., Primary Wood Processing - Principles and Practice, Springer, The Netherlands, 2006, chapter 13.

6. White, R. H., Effect of lignin content and extractives on higher heating value of wood. Wood Fiber Sci., 1987, 19(4), 446-452.

7. Senelwa, K. and Sims, R. E. H., Fuel characteristics of short rotation forest biomass. Biomass Bioenergy, 1999, 17, 127-140.

8. Moya, R. and Tenorio, C., Fuelwood characteristics and its relation with extractives and chemical properties of ten fast-growing species in Costa Rica. Biomass Bioenergy, 2013, 56, 14-21.

9. Bodirlau, R., Teaca, C. A. and Spiridon, I., Chemical modification of beech wood: effect on thermal stability. BioResources, 2008, 3, 789-800.

10. Technical Association of the Pulp and Paper Industry (1954). Holocellulose in Wood. Official Standard T19M-54, New York, TAPPI.

11. Demirbas, A., Relationships between lignin contents and heating values of biomass. Energy Convers. Manage., 2001, 42, 183-188.

12. Kataki, R. and Konwrer, D., Fuelwood characteristics of some indigenous woody species of northeast India. Biomass Bioenergy, 2001, 20, 17-23.

13. Kumar, R., Pandey, K. K., Chandrashekar, N. and Mohan, S., Study of age and height wise variability on calorific value and other fuel properties of Eucalyptus hybrid, Acacia auriculaeformis and Casuarina equisetifolia. Biomass Bioenergy, 2011, 35, 13391344.

ACKNOWLEDGEMENT. We thank the Karnataka Forest Department for providing experimental material for this work.

Received 25 September 2019; revised accepted 21 November 2019

doi: $10.18520 / \mathrm{cs} / \mathrm{v} 118 / \mathrm{i} 6 / 966-969$

\section{Smart automatic irrigation controller}

\author{
Faruk Poyen $^{1, *}$, Sayan Hazra ${ }^{1}$, \\ Nabarun Sengupta ${ }^{1}$, Apurba Ghosh ${ }^{1}$ and \\ Palash Kundu ${ }^{2}$
}

${ }^{1}$ University Institute of Technology, Golapbag (North), Burdwan 713 104, India

${ }^{2}$ Electrical Engineering, Jadavpur University, Kolkata 700 032, India

\begin{abstract}
Adherence to outdated irrigation techniques causes massive water wastage. In this article, a device is prototyped to curtail this wastage of water by optimizing the irrigation requirements. The design, named smart automatic irrigation controller (SAIC) measures the necessary parameters and determines evapotranspiration (ET) loss. The fuzzy rule based design, evaluates the process variables and generates an output regulation to compensate for the water loss due to ET. The model has two units, viz. wireless sensor unit (WSU) and wireless information processing unit (WIPU) to perform the stated operations. The device is connected
\end{abstract}

*For correspondence. (e-mail: faruk.poyen@gmail.com) 
to a cloud server for data repository and remote access and control. The novelty of the model is the design of the fuzzy rule base in the controller that dictates the regulation of the actuators. The prototype is handy and industry-ready for mass-scale application and usage as it has shown very high accuracy in both simulation and during dry-run.

Keywords: Agriculture, automatic controller, evapotranspiration, fuzzy logic, irrigation, sensors, SIAC.

FRESHWATER is an important natural resource that is required by the human society on this planet, but rapid urbanization and population increase are causing this resource to deplete at an alarming rate. Agriculture is very much neglected, leading to a few technological advancements in this domain. Agriculture has two facets, one is biotechnology and the other being irrigation methodology. In India, sticking to outdated irrigation methods has led to poor crop yield, wastage of water and increase in farming expenses. A substantial share of India's GDP is dependent on agriculture, and though the production is increasing, increase in population to increase in yield ratio is disproportionate.

India has a yield of $0.87 \mathrm{~kg} / \mathrm{m}^{3}$ compared to China, USA and England whose crop productivity is $2 \mathrm{~kg} / \mathrm{m}^{3}$. About $70 \%$ of the total annual water consumption (550 billion $\mathrm{m}^{3}$ ) is spent on the agricultural purpose, out of which $90 \%$ is solely used only to water the farms ${ }^{1}$. With traditional irrigation methods, 5000 litres of water is required for $1 \mathrm{~kg}$ of rice $^{2}$. A mere $10 \%-15 \%$ water utilization efficiency can bring about $40-50$ billion $\mathrm{kg}$ yield improvement. Hence it is of utmost importance to pick the right methods and enhanced techniques for irrigation practices. Agricultural modernization calls for controlled irrigation techniques. To accomplish this modernization, an irrigation controller is to be built to fit and cater all the irrigational needs for different types of crops for different climatic conditions across various growth stages ${ }^{3}$. The key features that an irrigation controller should be able to provide are high efficiency, low power consumption with minimal investment producing multi-functioning agricultural water-saving platform.

Allen et $a l^{4}$ developed an evapotranspiration (ET) and time-based irrigation system. Nemali and van Iersel $^{5}$ developed a solenoid valve-based controller measuring the volumetric water content of the soil. O'Shaughnessy and Evett $^{6}$ used a remote canopy temperature set-point technique for cotton farming. Feng et al. ${ }^{7}$ simulated wireless sensor network (WSN) to compare historical data and field data for the irrigation control scheme. $\mathrm{Wi}-\mathrm{Fi}^{8}$ and Zigbee ${ }^{9}$ wireless protocols were used as communication techniques. In order to figure out either free space model or multiple attenuation model, the expression for critical distance $d_{0}$ between sending and receiving node is provided in the below equation.

$$
d_{0}=\frac{4 \pi \sqrt{\alpha h_{\mathrm{r}}}}{\lambda} h_{\mathrm{t}}
$$

where $\alpha$ is the path loss exponent, $h_{\mathrm{r}}$ the receiver antenna height, $h_{\mathrm{t}}$ the transmitting antenna height and $\lambda$ is the signal wavelength.

Gutierrez et al. ${ }^{10}$ used sensor network with distributed wireless network for data collection and developed an algorithm for soil moisture and threshold temperature while designing the irrigation controller, which marked significant water savings. Parmenter et al. ${ }^{11}$ suggested a similar kind of control logic for sprinkler-based systems with the addition of web-based dynamics featuring intuitive graphical interface.

For proper management and monitoring and recording environmental parameters, wireless communication and networking have been used in the form of $\mathrm{WSN}^{12-14}$. Kim et $a l .{ }^{15}$ discussed software development for dedicated sprinkler control for site-specific irrigation as the exact positions of irrigation devices are known via global positioning system (GPS) equipment. Data acquisition systems were deployed for crop condition monitoring, which was downloaded in handheld devices via a serial port for analysis and storage ${ }^{16}$. Water flux leached below the root zone under an irrigated cropping system was measured using wick-type lysimeter ${ }^{17}$. Hybrid architecture and wireless modules were used inside the greenhouse, whereas wired modules were used in the outside as actuator controller $^{18}$. Development of microcontroller-based WSN communication technologies improved the response in real-time ${ }^{19}$, over a wide range of applications deployed in terrestrial, underground and underwater environments ${ }^{20}$.

Felix et al. ${ }^{21}$ designed soil moisture based stand-alone automatic irrigation system. Miranescu et al. ${ }^{22}$ emphasized the influence of air and soil temperature, relative humidity, soil moisture and ET on plant and crop growth. A new scheme of cyber-physical system (CPS) was proposed in their work advocating the integration of sensor data with a telemetry system for computation purposes. Avsar et $a l .^{23}$ developed a cloud-based irrigation system capable of driving sprinklers to compensate for water loss recorded by Class A pan evaporator. However, these researchers have limited their study on the controlled agricultural condition for strawberries only. The duration of irrigation as proposed by this team is provided in the below equation

$$
t=\frac{E_{\mathrm{pan}} * K_{\mathrm{cp}} * P * A}{q * n},
$$

where $E_{\mathrm{pan}}$ is the cumulative free surface water evaporation at irrigation interval $(\mathrm{mm}), K_{\mathrm{cp}}$ the plant-pan coefficient, $P$ the plant cover $(\%)$, a parameter related to the area of plant leaves, $A$ the field area $\left(\mathrm{m}^{2}\right), q$ the flow rate from the emitters and $n$ is the number of drippers in the field $^{24}$.

CURRENT SCIENCE, VOL. 118, NO. 6, 25 MARCH 2020 


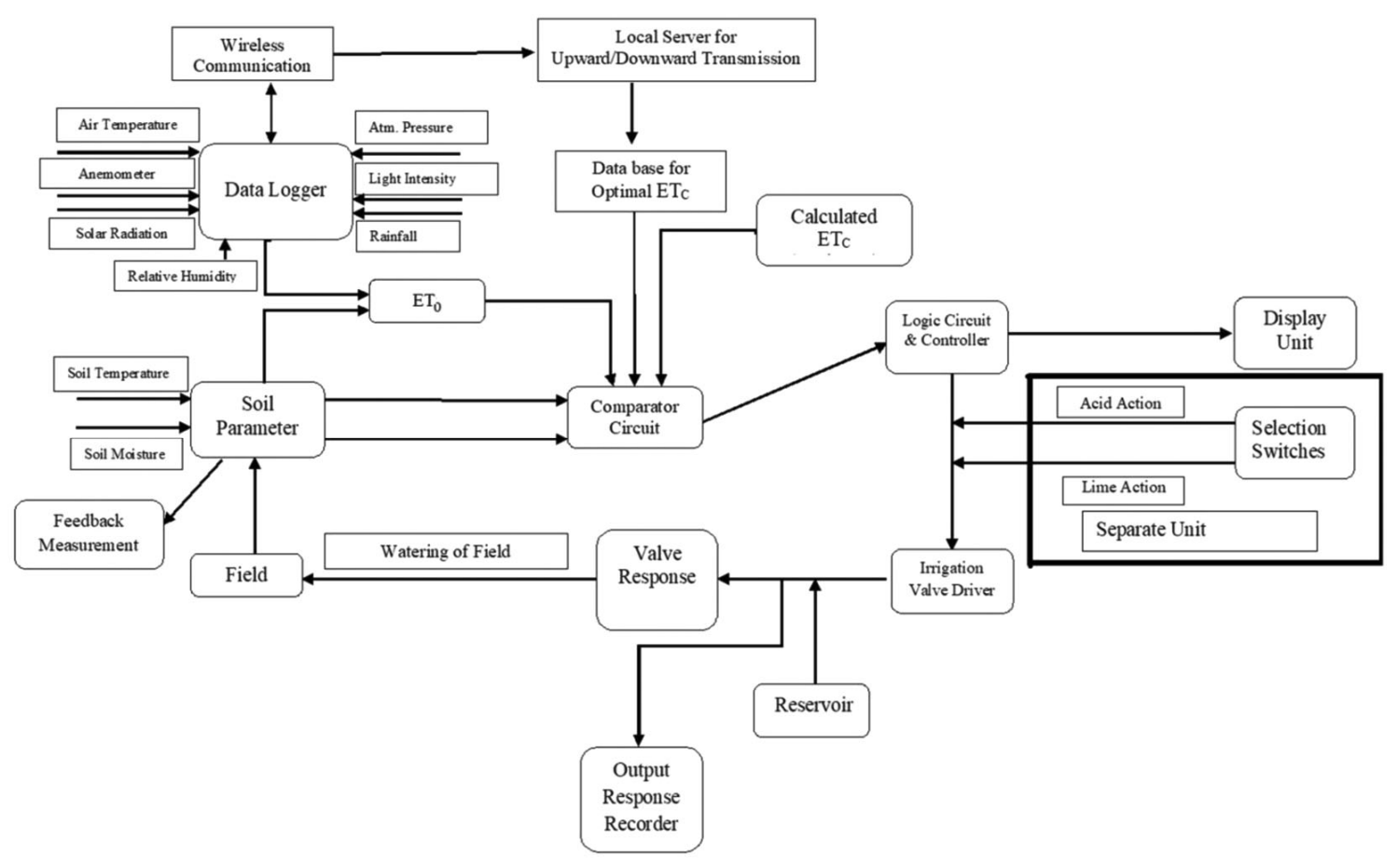

Figure 1. Block diagram of the smart automatic irrigation controller (SAIC).

Measuring atmospheric parameters, soil and crop type and requirements, offer significant information on the yield from previous practices and assist in calculating the next irrigation practice, which can be obtained by introducing a feedback loop in the controller ${ }^{25}$. Based on this and crop information, supplements can be added to the land to acquire the desired yield. There exist many automatic irrigation methods, viz. time-based, volume-based, open-loop, closed-loop and real-time feedback system. But the one that is the most desirable is the computer/ controller-based irrigation control system. Again, based on the complexity of the technology, it is also categorized as low-tech and high-tech methods. The initial setup is expensive with the requirement of constant power supply.

The model is based on compensating the water deficit between the optimum and actual levels present in the field. For this ET measurement plays a pivotal role. Necessary data are supplied by: (i) real-time weather and climatic sensor data, (ii) geographic locations, soil type and irrigation type and (iii) plantation type and growth stage.

The other important parameter is the soil moisture deficit (SMD), indicating the water requirement of the soil to maintain the field capacity. SMD is a function of incoming water, outgoing potential ET and water capacity available for plant use.

The ET is calculated from the following basic equa$\operatorname{tion}^{25}$

$$
\mathrm{ET}=\mathrm{I}+\mathrm{P}-\mathrm{RO}-\mathrm{DP}+\mathrm{CR} \pm \mathrm{DSF} \pm \mathrm{DSW} .
$$

$\mathrm{I}$ is the irrigation, $\mathrm{P}$ the rainfall, $\mathrm{RO}$ the run-off, DP the deep percolation, CR the capillary rise, DSF the subsurface flow in the root zone (negligible) and DSW is the subsurface flow out of the root zone (negligible).

The Penman-Monteith (PM) equation is a combined method for ET determination

$$
\mathrm{ET}_{0}=\frac{0.408 \Delta\left(R_{\mathrm{n}}-G\right)+\gamma \frac{900}{T+273} u_{2}\left(e_{\mathrm{s}}-e_{\mathrm{a}}\right)}{\Delta+\gamma\left(1+0.34 u_{2}\right)},
$$

$\mathrm{ET}_{0}$ is the reference evapotranspiration $\left(\mathrm{mm} \mathrm{day}^{-1}\right), R_{\mathrm{n}}$ the net radiation at the crop surface $\left(\mathrm{MJ} \mathrm{m}^{-2} \mathrm{day}^{-1}\right), G$ the soil heat flux density $\left(\mathrm{MJ} \mathrm{m}^{-2} \mathrm{day}^{-1}\right), T$ the mean daily air temperature at $2 \mathrm{~m}$ height $\left({ }^{\circ} \mathrm{C}\right), u_{2}$ the wind speed at $2 \mathrm{~m}$ height $(\mathrm{m} / \mathrm{s}), e_{\mathrm{s}}$ the saturation vapour pressure $(\mathrm{kPa}), e_{\mathrm{a}}$ the actual vapour pressure $(\mathrm{kPa}), e_{\mathrm{s}}-e_{\mathrm{a}}=e^{0}(T)$ the saturation vapour pressure deficit $(\mathrm{kPa}), D$ the slope vapour pressure curve $\left(\mathrm{kPa} /{ }^{\circ} \mathrm{C}\right), g$ the psychometric constant $\left(\mathrm{kPa} /{ }^{\circ} \mathrm{C}\right), P$ the atmospheric pressure $(\mathrm{kPa}), z$ the elevation above sea level $(\mathrm{m}), e^{0}(T)$ the saturation vapour pressure at the air temperature $T(\mathrm{kPa}), \lambda$ the latent heat of vaporization, $2.45\left[\mathrm{MJ} \mathrm{kg}^{-1}\right], C_{\mathrm{p}}$ the specific heat at constant pressure, $1.013 \times 10^{-3}\left[\mathrm{MJ} \mathrm{kg}^{-1}{ }^{\circ} \mathrm{C}^{-1}\right]$ and $\varepsilon$ is the ratio molecular weight of water vapour $/$ dry air $=0.622$. The other most efficient ET calculation methods are Kharrufa method $^{26}$ (temperature-based; eq. (5)) ${ }^{26}$ and Hargreaves method (radiation-based; eq. (6)). It has to be evaluated and determined which manner is more efficient and accurate for what kind of climatic and geographic conditions. 


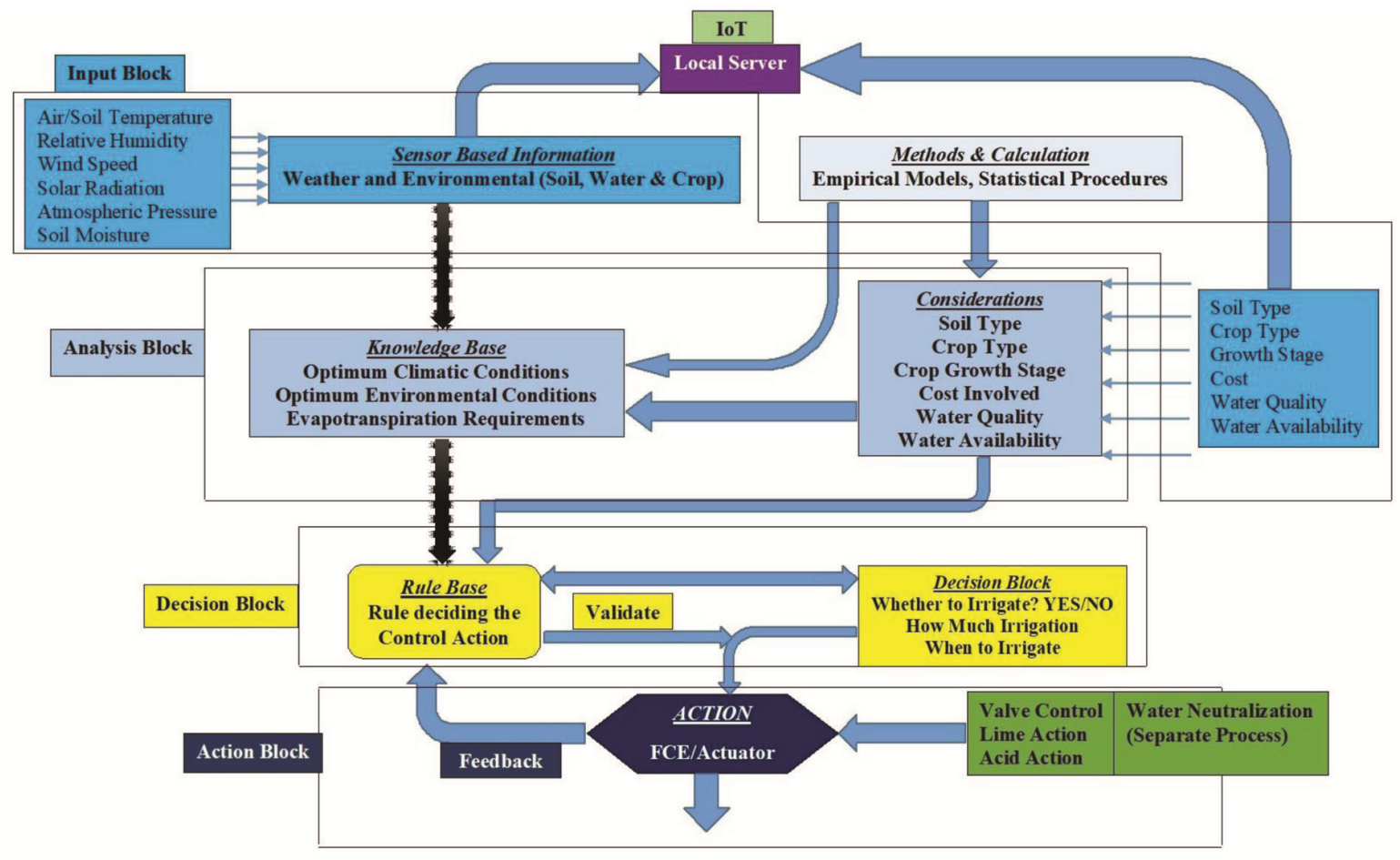

Figure 2. Workflow of the four functional blocks of SAIC.

Based on this information, the controller will first decide on the mode to use for ET determination and then decide on the amount of water to be supplied to the field to maintain the optimal conditions.

$$
\begin{aligned}
& \mathrm{ET}=0.34 * p * T_{a}^{1.3} \\
& \mathrm{ET}_{0}=0.0135 R_{\mathrm{s}}\left(T_{\text {mean }}+17.8\right),
\end{aligned}
$$

where $p$ is the percentage of total daytime hours for the period of measurement, $T_{a}$ the mean monthly temperature, $R_{\mathrm{s}}$ the solar radiation and $T_{\text {mean }}$ is the daily mean temperature.

A schematic block diagram of the smart automatic irrigation controller (SAIC), highlighting the major operations is shown in Figure 1. A supplementary process is provided, which sees to the fact that once the water is fed to the farmland, its $\mathrm{pH}$ level is maintained at desirable levels ${ }^{27}$.

Figure 2 shows the workflow of the four functional blocks namely, input block, analysis block, decision block and action block. The analysis block is rich with a strong database that supplies the controller with all the information related to the crop type, stage of growth, soil type and optimal ET values for all the different combinations.

The system acquires data from the sensor network and, ET is calculated which provides information on water level presently available on the field. The fuzzy inference system (FIS) comprising the rule-base evaluates different input combinations and provides the necessary output. Three parameters, i.e. crop type, soil type and growth stage, combine to formulate the rule-base to cater to different requirements. Depending on the necessity, triangular and trapezoidal membership functions are used. The output of this rule-base will provide the exact compensation required to meet the water loss. Figure 3 represents the fuzzy-controlled simulation model.

The input parameters considered in developing the rule-base are four types of crops, such as rice, wheat, maize and barley and four soil types, viz. sandy, loam, clay and silt. The growth stages are divided into five, i.e. tillering, panicle initiation, booting and flowering and finally ripening.

SAIC has two units, namely wireless sensor unit (WSU), for measuring, recording climatic data and calculating ET value and subsequent uploading in cloud server; and wireless information processing unit (WIPU), situated elsewhere, to process the data from cloud and apply the rule-base to initiate the control action, i.e. how much compensation is required to meet the ET loss. WSU can select among the three major ET evaluating processes, proposed by PM, Kharrufa and Hargreaves, as per the demand. Thus the irrigation controller provides more flexibility to the user to accommodate the specific kind of requirement. The climatic parameters measured are air temperature, relative humidity, soil moisture content, soil temperature, solar radiation, wind speed, rainfall, atmospheric pressure and light intensity. Figure 4 illustrates the internal circuit connection in WSU of SAIC.

The selection considerations that are to be made by WSU and WIPU are: (i) soil type by WSU, (ii) crop type 


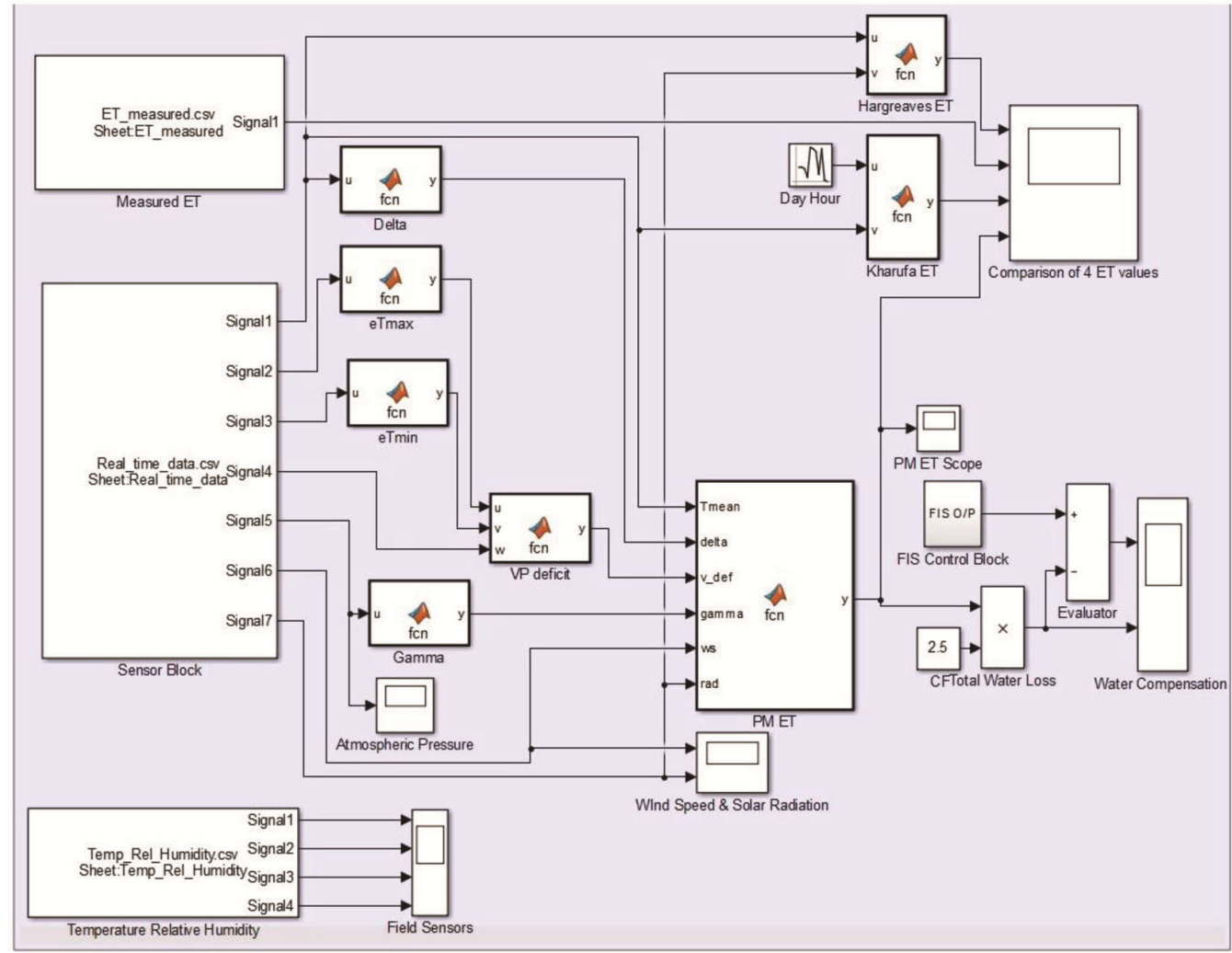

Figure 3. Simulation block diagram of SAIC.

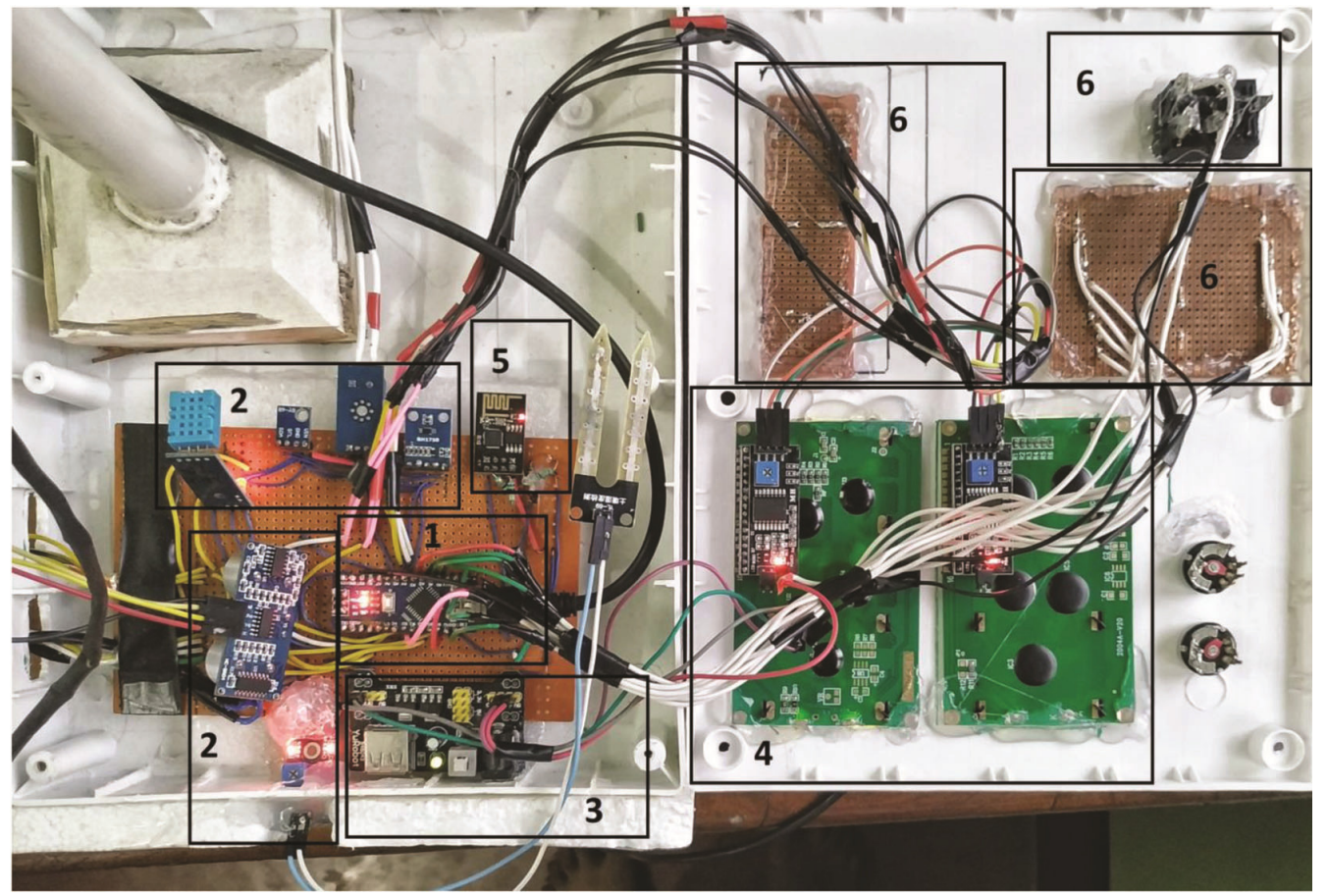

Figure 4. Internal circuit connection of the WSU. 1, MCU; 2, sensor nodes; 3, power supply unit; 4, display unit; 5, Wi-Fi unit; 6, power switch and switch units.

by WSU, (iii) irrigation type by WIPU and (iv) microclimate by WIPU.

The checklist for the controller is: (i) soil, crop type, growth stage, (ii) controller, (iii) obstructions, (iv) wear and tear of pump and (v) valves, serge and water pressure.

Figure 5 shows the ET values obtained under PM, Kharrufa and Hargreaves methods along with actual 


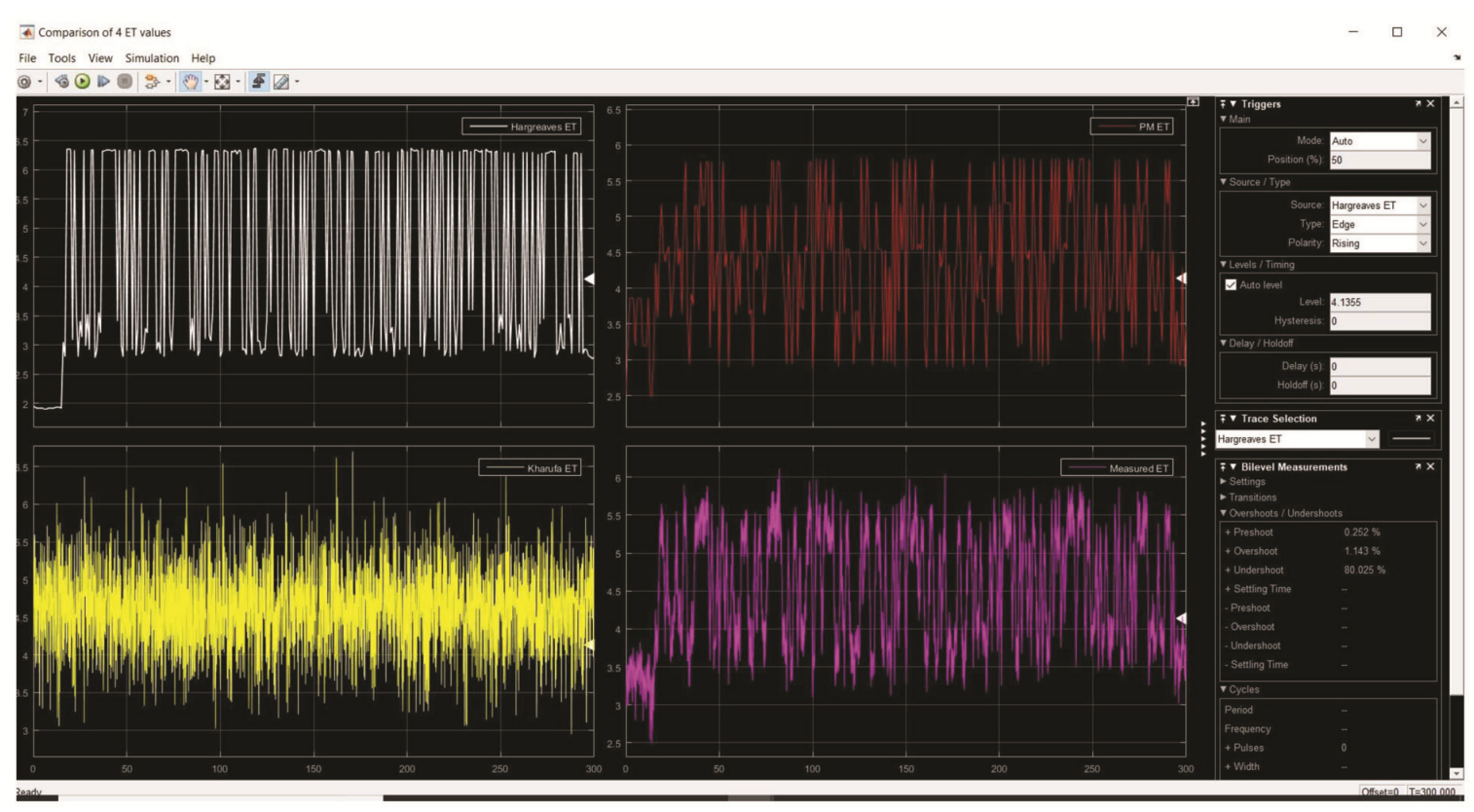

Figure 5. Comparison between four evapotranspiration methods.

value as measured by a lysimeter. The four results are in close congruence with each other, thus making all the three methods highly acceptable.

The output obtained after running the simulation model is shown in Figure 6 which shows that the water lost due to ET has been perfectly compensated by the fuzzy rulebase, thus appropriating the water level of the field. The orange line denotes the volume of water lost due to ET, and the yellow line signifies the volume compensated. Hence, the target objective is fulfilled with high efficiency.

The study area is Burdwan, West Bengal, India $\left(23^{\circ} 15^{\prime} 20^{\prime \prime} \mathrm{N}, 87^{\circ} 51^{\prime} 24^{\prime \prime} \mathrm{E}\right)$, a dominant agriculture belt, from where data were collected and analysed. The field study was carried out on 1 ha of farming land of sandy alluvial type and slightly acidic, low in nitrogen, calcium, phosphate and other plant nutrients ${ }^{28}$. Climate is tropical, and altitude is $32 \mathrm{~m}$ with an average annual temperature of $26.3^{\circ} \mathrm{C}$. The temperature variation throughout the year is $11.5^{\circ} \mathrm{C}$, and the difference of precipitation between the driest and wettest months is $307 \mathrm{~mm}$. April and January are the warmest and coldest months with an average maximum of $30.9^{\circ} \mathrm{C}$ and minimum of $19.4^{\circ} \mathrm{C}$ respectively. The Köppen-Geiger climate classification is Aw (Tropical, Savanna wet). The average rainfall is $1313 \mathrm{~mm}$.

The experimental test run was conducted on rice (staple crop) cultivation, which is primarily a Kharif crop. The study period was 140 days from the fallow period to the harvesting, for a medium duration rice variant, between 10 November 2018 and 31 March 2019. The cultivation season was of Aman type, i.e. the seeds are sown in winter and harvested in summer, receiving mild to no rainfall, hence depending on irrigation water. The study region was divided into four zones, each having a separate WSU comprising thinly netted sensor network.
Climatic and field data were collected and recorded every day. Also, the soil $\mathrm{pH}$ value was recorded. As the $\mathrm{pH}$ values varied between 6.6 and 7.5 during the entire period, which was optimum for rice growth, no neutralization action was required. Sporadic rainfalls were received. For the first 30 days, water level was maintained at $8 \mathrm{~cm}$, the next 80 days, the water level was maintained at $15 \mathrm{~cm}$. Earlier studies have showed that about $40 \%$ of the required water will be lost in ET and $60 \%$ in percolation $^{2}$. Thus, after determining the daily value of ET, 2.5 times of the same was recouped to the field to maintain the required balance of water table in the area. Table 1 shows the monthly average of the data collected from sensors, calculated ET obtained from WSU and actual ET measured from a weighing lysimeter. The results showed that the ET value calculated was almost equal to the lysimeter ET value, and hence, it could be concluded that the calculated ET was correct. These data were obtained from the pilot smart weather station that was built during the process of this experiment, and the results were validated with official weather stations.

Table 2 compares the harvest of rice for the Boro season between 2017-18 and 2018-19. The cultivation period in both cases was 140 days, with approximately the same climatic conditions. The amount of water required to cultivate one acre of land without and with the employment of SAIC was 1.9 and 1.47 million gallons respectively. The yields before and after SAIC applications were 2.2 and 3.1 tonnes respectively. Saving of $22.63 \%$ of irrigation water and $40 \%$ of the increase in yield were recorded following the application of SAIC. However, there were other factors also like weed and pest control, and monitoring the usage of fertilizers that contributed to the increase of yield. 
RESEARCH COMMUNICATIONS

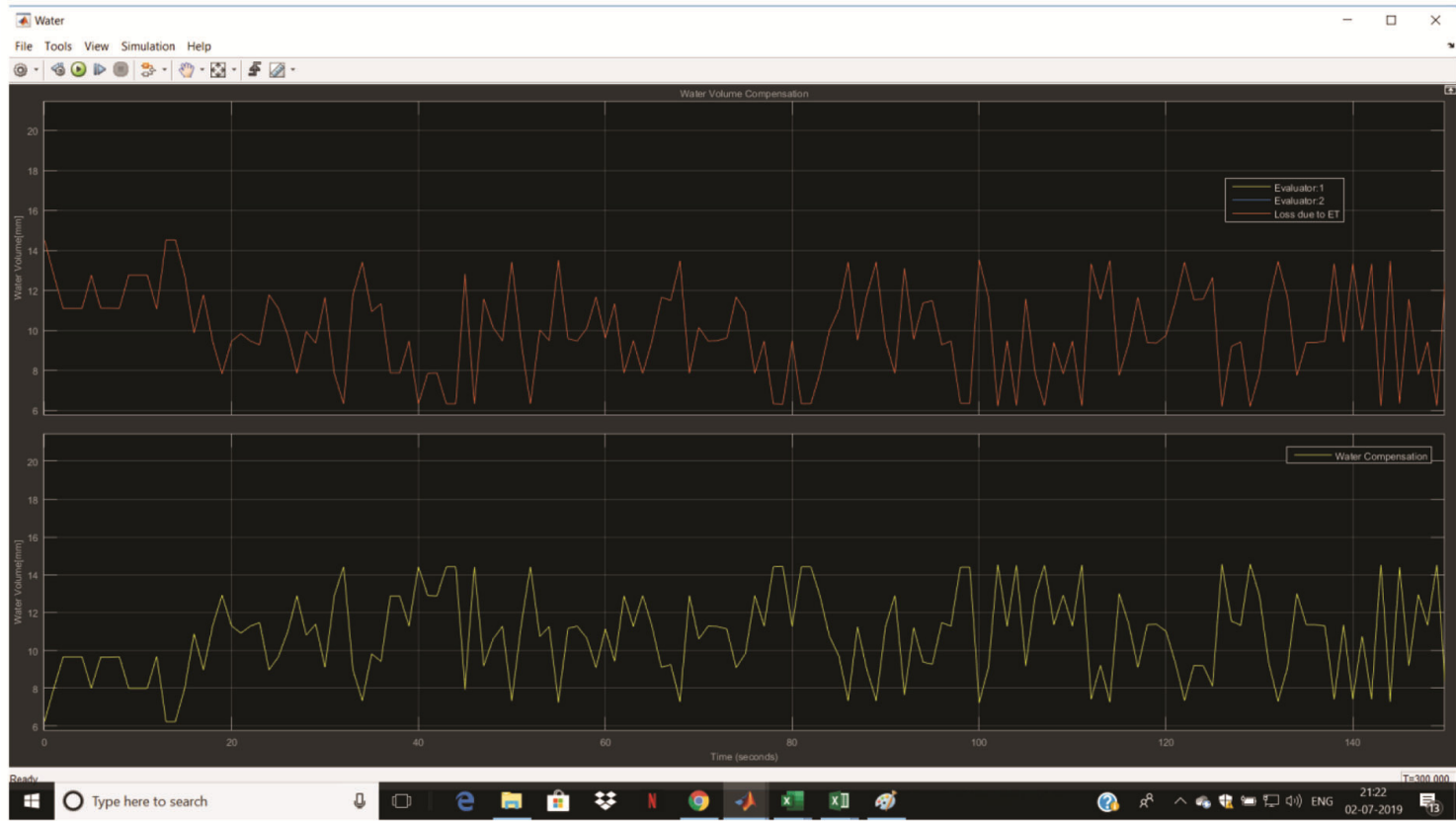

Figure 6. Simulation output showing volume compensation.

Table 1. Monthly average climatic data for the cultivation period

\begin{tabular}{lrrrrr}
\hline Parameters & November & December & January & February & March \\
\hline Air temperature $\left({ }^{\circ} \mathrm{C}\right)$ & 28.4 & 20.3 & 19.8 & 24.9 & 31.5 \\
Soil temperature $\left({ }^{\circ} \mathrm{C}\right)$ & 33 & 31 & 26 & 29 & 34.5 \\
Relative humidity $(\%)$ & 65 & 63 & 62 & 70 & 68 \\
Solar radiation $\left(\mathrm{kWh} / \mathrm{m}^{2} /\right.$ day) & 4.89 & 4.67 & 4.32 & 5.01 & 5.44 \\
Wind speed $(\mathrm{km} / \mathrm{h} \mathrm{NE})$ & 3 & 4 & 1 & 2 & 3 \\
Rainfall (mm) & 38 & 33 & 28 & 27 & 133 \\
Atmospheric pressure (mbar) & 1014 & 1014 & 1015 & 1013 & 1013 \\
WSU ET (mm) & 2.89 & 2.23 & 2.01 & 2.52 & 3.17 \\
Lysimeter ET (mm) & 2.81 & 2.25 & 2.11 & 2.43 & 3.12 \\
\hline
\end{tabular}

WSU, Wireless sensor unit; ET, Evapotranspiration.

Table 2. Comparison of harvest between seasons 2017-18 and 2018-19

\begin{tabular}{lll}
\hline & \multicolumn{1}{c}{$\begin{array}{c}2017 \\
\text { Period }\end{array}$} & $\begin{array}{c}2018 \\
\text { (period 10 November 2017-1 April 2018) }\end{array}$ \\
\hline Crop season & Aman & Aman \\
Crop type & Paddy (rice) & Paddy (rice) \\
Farm size (acre) & $1\left(61 \times 66 \mathrm{~m}^{2}\right)$ & $1\left(61 \times 66 \mathrm{~m}^{2}\right)$ \\
Cultivation period (days) & 141 (fallow to harvest) & 140 (fallow to harvest) \\
Rainfall received (cm) & 740 & 770 \\
Water pH & Varied between 6.5 and 7.5 (optimum) & Varied between 6.5 and 7.5 (optimum) \\
Soil pH & Varied between 6.9 and 7.6 (optimum) & Varied between 6.9 and 7.7 (optimum) \\
Water supplied (million gallon) & 1.9 & 1.47 \\
Water usage (\%) & & $26.63 \%$ less water used \\
Crop harvest (tonnes) & 2.2 & 3.1 \\
Harvest improvement (\%) & & \\
$40 \%$ increase in harvest & & \\
Water/kg rice & 3269 litres $/ \mathrm{kg}$ & 1795 litres $/ \mathrm{kg}$ \\
\hline
\end{tabular}

As anticipated, the results obtained from SAIC were significantly accurate, and the output obtained was substantially in congruence with our expectation. Both crop yield and water usage showed improvement as $26.63 \%$ water saving was recorded with an increase of $40 \%$ yield. The prototype is suitable for any crop type and for any 
soil type across different stages of growth globally. This feature makes it a unique irrigation controller setup. The ease of operation and low cost, robustness and accuracy are the unique selling points of this device. Large scale production of this device will further bring down the price, and it has the potential to cater to all types of cultivators. The data uploaded can be accessed by other researchers providing the platform for live feedback and discussion on the betterment of the process. Thus, it can have a significant impact on the irrigation scheduling process and agriculture in the long run. The device can be integrated for commercial usage at an expense of a mere 50 USD.

1. Poyen, F., Automated watering system for agricultural fields. Int. J. Adv. Electron. Eng., 2012, 2(3), 104-107.

2. Agropedia.iitk.ac.in, irrigation water management in paddy agropedia, 2018; http://agropedia.iitk.ac.in/content/irrigation-watermanagement-paddy

3. Irrigation.org, 2019; https://www.irrigation.org/IA/FileUploads/ IA/Advocacy/Principles_of_Efficient_Agriculture_Irrigation_7$17 . \mathrm{pdf}$

4. Allen, R., Crop evapotranspiration-guidelines for computing crop water requirements - FAO irrigation and drainage paper 56 . Food and Agriculture Organization, United Nations, Rome, 1998, pp. $1-15$.

5. Nemali, K. and van Iersel, M., An automated system for controlling drought stress and irrigation in potted plants. Sci. Hortic., 2006, 110(3), 292-297; doi:10.1016/j.scienta.2006.07.009.

6. O'Shaughnessy, S. and Evett, S., Canopy temperature-based system effectively schedules and controls centre pivot irrigation of cotton. Agric. Water Manage., 2010, 97(9), 1310-1316; doi:10. 1016/j.agwat.2010.03.012.

7. Feng, Z., Research on water-saving irrigation automatic control system based on internet of things. In International Conference on Electric Information and Control Engineering, Wuhan, China, 2011, pp. 2541-2544; doi:10.1109/iceice.2011.5778297.

8. IEEE Standard for Information Technology - telecommunications and information exchange between systems - local and metropolitan networks-specific requirements - Part 11: wireless LAN medium access control (MAC) and physical layer (PHY) specifications: higher speed physical layer (PHY) extension in the 2.4 GHz band, 2000; doi:10.1109/ieeestd.2000.90914.

9. IEEE Standard for Information Technology - local and metropolitan area networks - specific requirements - Part 15.4: wireless medium access control (MAC) and physical layer (PHY) specifications for low rate wireless personal area networks (WPANs), 2006; doi:10.1109/ieeestd.2006.232110.

10. Gutierrez, J., Villa-Medina, J., Nieto-Garibay, A. and PortaGandara, M., Automated irrigation system using a wireless sensor network and GPRS module. IEEE Trans. Instrum. Meas., 2014, 63(1), 166-176; doi:10.1109/tim.2013.2276487.

11. Parmenter, J., Jensen, A. and Chiu, S., Smart irrigation controller. In IEEE International Conference on Electro/Information Technology, Milwaukee, 2014, pp. 394-398; doi:10.1109/eit.2014. 6871796.

12. Wang, N., Zhang, N. and Wang, M., Wireless sensors in agriculture and food industry - recent development and future perspective. Comput. Electron. Agric., 2006, 50(1), 1-14; doi:10.1016/ j.compag.2005.09.003.

13. Chaudhary, D., Nayse, S. and Waghmare, L., Application of wireless sensor networks for greenhouse parameter control in precision agriculture. Int. J. Wireless Mobile Networks, 2011, 3(1), 140149; doi:10.5121/ijwmn.2011.3113.
14. Marino, P., Fontan, F., Dominguez, M. and Otero, S., An experimental ad-hoc WSN for the instrumentation of biological models. IEEE Trans. Instrum. Meas., 2010, 59(11), 2936-2948; doi: 10.1109/tim.2010.2045970.

15. Kim, Y., Evans, R. and Iversen, W., Remote sensing and control of an irrigation system using a distributed wireless sensor network. IEEE Trans. Instrum. Meas., 2008, 57(7), 1379-1387; doi:10.1109/tim.2008.917198.

16. Fisher, D. and Kebede, H., A low-cost microcontroller-based system to monitor crop temperature and water status. Comput. Electron. Agric., 2010, 74(1), 168-173; doi:10.1016/j.compag. 2010.07.006.

17. Kim, Y., Jabro, J. and Evans, R., Wireless lysimeters for real-time online soil water monitoring. Irrigation Sci., 2010, 29(5), 423430; doi:10.1007/s00271-010-0249-x.

18. Mirabella, O. and Brischetto, M., A hybrid wired/wireless networking infrastructure for greenhouse management. IEEE Trans. Instrum. Meas., 2011, 60(2), 398-407; doi:10.1109/tim.2010. 2084250.

19. Akyildiz, I., Su, W., Sankarasubramaniam, Y. and Cayirci, E., A survey on sensor networks. IEEE Commun. Mag., 2002, 40(8), 102-114; doi:10.1109/mcom.2002.1024422.

20. Yick, J., Mukherjee, B. and Ghosal, D., Wireless sensor network survey. Comput. Networks, 2008, 52(12), 2292-2330; doi: 10.1016/j.comnet.2008.04.002.

21. Felix, A., Orovwode, H., Awelewa, A., Wara, S. and Tobiloba, O., Design and implementation of an automatic irrigation system based on monitoring soil moisture. J. Electr. Eng., 2016, 16, 206215.

22. Marinescu, T. et al., Advanced control strategies for irrigation systems. In 9th IEEE International Conference on Intelligent Data Acquisition and Advanced Computing Systems: Technology and Applications (IDAACS), Bucharest, 2017, pp. 843-848; doi:10.1109/idaacs.2017.8095206.

23. Avsar, E., Bulus, K., Saridas, M. and Kapur, B., Development of a cloud-based automatic irrigation system: A case study on strawberry cultivation. In 7th International Conference on Modern Circuits and Systems Technologies (MOCAST), Thessaloniki, 2018, pp. 1-4; doi:10.1109/mocast.2018.8376641.

24. Taş, İ. and Kirnak, H., Empirical models used in the estimation of crop evapotranspiration in semi-arid region of Turkey. $A D U$ Ziraat Fakültesi Dergisi, 2011, 8(1), 57-66.

25. Romero, R., Muriel, J., García, I. and Muñoz de la Peña, D., Research on automatic irrigation control: state-of-the-art and recent results. Agric. Water Manage., 2012, 114, 59-66; doi:10.1016/ j.agwat.2012.06.026.

26. Poyen, F., Kundu, P. and Ghosh, A., Temperature based ET method selection for Burdwan district in WB, India. Int. J. Appl. Eng. Res., 2018, 13(16), 12753-12763.

27. Poyen, F., Kundu, P. and Ghosh, A., pH control of untreated water for irrigation. J. Inst. Eng. (India): Series A, 2018, 99(3), 539546; doi:10.1007/s40030-018-0297-4.

28. Bardhaman.nic.in, Geography: Burdwan District, 2018; http://www.bardhaman.nic.in/geography.html

Received 31 July 2019; revised accepted 21 November 2019

doi: $10.18520 / \mathrm{cs} / \mathrm{v} 118 / \mathrm{i} 6 / 969-976$ 